\title{
Biomarkers for prostate cancer: present challenges and future opportunities
}

Prostate cancer ( $\mathrm{PCa}$ ) has variable biological potential with multiple treatment options. A more personalized approach, therefore, is needed to better define men at higher risk of developing $\mathrm{PCa}$, discriminate indolent from aggressive disease and improve risk stratification after treatment by predicting the likelihood of progression. This may improve clinical decision-making regarding management, improve selection for active surveillance protocols and minimize morbidity from treatment. Discovery of new biomarkers associated with prostate carcinogenesis present an opportunity to provide patients with novel genetic signatures to better understand their risk of developing PCa and help forecast their clinical course. In this review, we examine the current literature evaluating biomarkers in $\mathrm{PCa}$. We also address current limitations and present several ideas for future studies.

Lay abstract: Several biological markers as well as collections of genetic mutations have been identified by researchers that are associated with the development and aggressiveness of prostate cancer. They can also predict death from prostate cancer in combination with other known risk factors. Some are commercially available for use in current clinical practice. These personalized genetic profiles can help select patients that are most likely to benefit from definitive treatment with either surgery or radiation therapy. Future studies, however, need to focus on biological manipulation of known high-risk genes to reduce the incidence of this disease for future generations.

First draft submitted: 29 June 2015; Accepted for publication: 10 August 2015; Published online: 17 December 2015

Keywords: biomarkers $\bullet$ circulating tumor cells $\bullet$ diagnosis $\bullet$ genetic panels $\bullet$ prognosis - prostate cancer

\section{Background}

Prostate cancer $(\mathrm{PCa})$ remains the most common urologic malignancy and the second most common cause of cancer death for men in developed countries [1]. Since the advent of early detection efforts such as PSA screening and increased public awareness, PCa is frequently diagnosed in its initial stages. Reports over the past decade also indicate that a significant percentage of men with newly diagnosed PCa may be managed by active surveillance (AS) [2]. PCa screening, however, is still controversial since early detection can lead to the diagnosis and overtreatment of clinically insignificant disease with long-term effects on patient quality of life $[3,4]$. Additionally, no reliable screening tool exists that can consistently differentiate indolent versus potentially life-threatening disease [5].

A personalized, patient-centered approach to both the diagnosis and treatment of $\mathrm{PCa}$ is necessary due to the variability in disease behavior as well as the multitude of treatment options. Additionally, an individualized approach may improve prognostic criteria
Pranav Sharma', Kamran Zargar-Shoshtari' \& Julio M Pow-Sang*,1

'Department of Genitourinary Oncology, Moffitt Cancer Center, 12902 Magnolia Drive, Office 12538, Tampa, FL 33612, USA

*Author for correspondence:

Tel.: +1 8137452226

Fax: +18137458494

julio.powsang@moffitt.org 
and minimize the risk of unnecessary treatment and any associated impairment in quality of life.

Improvements in technology aimed at genetic analysis have led to the discovery of an abundance of new biomarkers that may be utilized in the prediction of PCa incidence, outcomes and response to therapy [6]. The characterization of genetic mutations in tumor tissue through advanced technologies, such as microarray analyses and next-generation sequencing, can subsequently create personalized road maps to guide clinical decision-making due to a better understanding of a patient's risk of progression [7].

We have summarized below the utilization of PCa biomarkers in current clinical practice, their limitations and possible future considerations for their use. We discuss the potential application of biomarkers as a screening or diagnostic tool in men at high risk of developing $\mathrm{PCa}$ and as a prognostic tool to discriminate indolent versus aggressive disease, aiming to improve treatment strategies in PCa patients at either a localized or advanced stage. Metabolomic PCa biomarkers, which have recently come to the forefront as a noninvasive investigational tool for PCa detection using in vivo magnetic resonance spectroscopy (MRS), are not discussed in the following review as they have yet to develop mainstream utilization in current clinical practice $[8,9]$. There is a growing body of evidence, however, that supports the inclusion of MRS in PCa diagnosis and treatment due to their improved sensitivity and specificity in predicting disease prognosis and for patient stratification through the metabolic fingerprint of different biofluids [10-14].

\section{Genetic risk factors in $\mathrm{PCa}$}

Family history of PCa in first-generation male relatives is a well-recognized risk factor for developing the disease with twin studies suggesting that greater than $40 \%$ of $\mathrm{PCa}$ risk is inheritable [15]. Through the Human Genome Project, analysis of constitutional DNA has shown over 60 PCa susceptibility loci explaining approximately a third of the familial risk have been identified, and multiple single nucleotide polymorphisms (SNPs) have been correlated with risk of developing disease [16,17]. Individuals carrying five of these risk alleles were almost tenfold more likely to develop PCa than men carrying no risk alleles (odds ratio [OR]: 9.46), but inclusion of this genotype did not add significantly in the prediction of PCa when added to established risk factors such as age and family history [18].

Rarer variants may be associated with higher relative PCa risk [19]. Coding variants in the homeobox B13 (HOXB13) were found in $<0.1 \%$ of controls, but $1.4 \%$ of patients with a strong family history of early-onset
PCa [20]. Although PCa risk stratification including genetic variants are currently limited since they do not add appreciably to the utility of more established clinical risk factors, inclusion of higher-risk variants may improve the performance of these models.

Germline BRCA mutations, which have dramatic genetic implications in breast and ovarian cancer, have also been associated with PCa. BRCA1 and BRCA2 play central roles in DNA repair by homologous recombination, which is the mechanism that cells use to repair double-stranded breaks induced, for example, by platinum-based chemotherapeutic agents or ionizing radiation (XRT). Previous studies have demonstrated that BRCA1 and BRCA2 mutations are predictive factors for response to platinum-based chemotherapy in breast and ovarian cancer [21,22]. BRCA2 mutations have subsequently been shown to confer a higher risk of PCa in men $\leq 65$ years of age (OR: 8.6) [23], and they were an independent prognostic factor for disease-specific survival (DSS) in all stages of PCa including localized disease [24]. Castro et al. evaluated tumor features and outcomes of 1302 patients with local or locally advanced $\mathrm{PCa}$ (including $67 \mathrm{BRCA}$ mutation carriers) and found that at 3,5 and 10 years after treatment (radical prostatectomy [RP] or XRT), noncarriers were more likely to be free from metastasis than carriers ( 97 vs $90 \%, 94$ vs $72 \%$ and 84 vs $50 \%$, respectively, [p < 0.001]). Noncarriers also had better 3-, 5- and 10 -year cancer-specific survival (CSS) rates than carriers ( 99 vs $96 \%, 97$ vs $76 \%$ and 85 vs $61 \%$, respectively, $[\mathrm{p}<0.001])[25]$.

Genetic characterization may play an important clinical role in the future. HOXB13, for example, is associated with low-risk $\mathrm{PCa}$, while $B R C A 2$ is associated with intraductal carcinoma, an early-onset aggressive PCa with a poor prognosis [26]. These susceptibility genes are also racially and ethnicity dependent and act in an additive fashion. Genotyping all men at susceptibility loci, however, could also lead to the overdiagnosis and overtreatment of potentially indolent $\mathrm{PCa}$, subjecting more patients to the morbidity associated with treatment. It is our hope that screening and preventative therapy could be tailored according to risk stratification algorithms incorporating genetic mapping along with family history [27].

\section{Biomarkers in PCa diagnosis}

Prostate-specific antigen \& its derivatives

The most common current screening test for $\mathrm{PCa}$ is a measurement of the serum concentration of prostatespecific antigen (PSA), which currently cannot reliably predict adverse pathological features [28]. Additionally, there is no single cutoff value for PSA that can accurately distinguish patients with PCa from those with- 
out [29]. Age-specific upper reference limits for serum total PSA have been created and adjusted according to race (i.e., Caucasian, African-American, etc.) [30,31], and percent-free PSA (free-to-total PSA ratio) may also improve the performance of PSA-based testing [32]. SNPs at six loci have additionally been identified that indicate a significant association between PSA levels and patients without PCa, suggesting that PSA thresholds for biopsy could be personalized based on the patient's genotype at these loci [33]. A brief description of the various PSA-based tests frequently utilized in clinical practice is listed in Table 1, and a summary of commercially available biomarkers commonly used in clinical practice for PCa detection is listed in Table 2.

\section{PSA kinetics (velocity \& doubling time)}

There has been considerable uncertainty about PSA kinetics for decisions about prostate biopsy for diagnosis. Recent studies, including analyses of cohorts from all the major randomized trials of localized $\mathrm{PCa}$, have failed to find any evidence that PSA velocity (PSAV) and application of PSA cut points are of benefit in screening. Additionally, PSA dynamics are related to cancer growth rates only partially due to both malignant and nonmalignant processes contributing to PSA fluctuations. Nevertheless, PSA dynamics have been claimed to aid in the long-term prediction of $\mathrm{PCa}$ detection [38], and guidelines for PCa diagnosis include a recommendation that men with a PSAV greater than $0.35 \mathrm{ng} / \mathrm{ml}$ per year should consider biopsy even if their total PSA is low [39]. Others, however, have refuted the concept that the rate of change of PSA is of any value [40]. A brief definition of PSA kinetics is provided in Table 1.

Ulmert et al. tested whether PSAV improved the accuracy of a model using PSA level to predict long-term risk of PCa diagnosis in 4907 screened men (of which 443 [9\%] were diagnosed with PCa) [41]. The authors found that PSAV correlated strongly with PSA level $(r=0.93)$ and that adding PSAV did not significantly increase the accuracy of PSA to predict PCa development. These results were also unchanged, if the analysis was restricted to patient with advanced cancer at diagnosis.

In a systemic review of PSA kinetics in the diagnosis of PCa, PSAV added little predictive value to PSA alone (area under curve [AUC] $=0.83$ vs 0.81) [42]. Several other groups have reported that PSAV and PSA doubling time (PSADT) failed to improve the specificity of PSA for biopsy [43,44]. PSAV was not shown to aid in PCa detection in men with prior negative biopsies [45]. Data from the REDUCE trial also clearly indicate that changes in PSAV are unable to predict the risk of a repeat positive biopsy after initially negative findings [46]. In a study from the PCPT, PSAV added very little to the AUC of standard predictors alone ( 0.709 vs 0.702) with no improvement in the detection of highgrade cancer (0.792 reduced to 0.791) [47]. Using PSAV did not improve the sensitivity of PSA and would lead to many additional biopsies per year without a corresponding increase in the number of high-grade cancers detected.

Conversely, there are several studies that advocate the use of PSAV and PSADT in addition to total PSA for the detection of PCa. In a retrospective cohort of 219,388 men with at least three PSA measurements, Wallner et al. reported that the annual percent change in PSA accurately predicted the presence of $\mathrm{PCa}$ $(A U C=0.963)$ and the presence of aggressive disease $(A U C=0.955)$ with more accuracy than a single measurement of PSA alone (AUC = 0.727) [34]. Orsted et al. also showed that when long-term PSAV was added to models already including the baseline PSA value, the age-adjusted hazard ratio (HR) for PCa detection and PCa-related death increased from 2.7 to 5.3 and from 2.3 to 3.4 , respectively [48]. The authors, therefore, concluded that long-term PSAV in addition to baseline

\section{Table 1. Description of prostate-specific antigen-based markers utilized in clinical practice for} prostate cancer diagnosis.

\begin{tabular}{|ll|}
\hline $\begin{array}{l}\text { Marker } \\
\text { Age-adjusted PSA }\end{array}$ & $\begin{array}{l}\text { Description } \\
\text { Age-specific reference limits for serum total PSA stratified by race (i.e., Caucasian, } \\
\text { African-American) }\end{array}$ \\
\hline PSA doubling time & Time in months or years for the total PSA to double \\
\hline PSA velocity & The rate of change of PSA measured in ng/ml per year (change in PSA over time) \\
\hline Free PSA & Serum PSA unbound to alpha-1-anti-chymotrypsin \\
\hline Percent-free PSA & Ratio of free PSA to total PSA \\
\hline ProPSA & $\begin{array}{l}\text { The precursor of PSA, which is an inactive } 224 \text {-amino acid protein secreted by } \\
\text { prostatic cells }\end{array}$ \\
\hline PSA density & Total PSA divided by PSA volume (length $\times$ width $\times$ height $\times \pi / 6$ ) in ml or cc \\
\hline PSA: Prostate-specific antigen.
\end{tabular}


Table 2. Commercially available biomarkers utilized in clinical practice for prostate cancer diagnosis.

\begin{tabular}{|c|c|c|c|c|c|c|}
\hline Panel & Specimen & Description & $\begin{array}{l}\text { AUC for } \mathrm{PCa} \\
\text { detection }\end{array}$ & $\begin{array}{l}\text { Sensitivity } \\
(\%)\end{array}$ & $\begin{array}{l}\text { Specificity } \\
(\%)\end{array}$ & Ref. \\
\hline PCA3 & Urine & $\begin{array}{l}\text { Measures noncoding RNA } \\
\text { only expressed in human } \\
\text { prostate tissue }\end{array}$ & 0.658 & 66 & 76 & [34] \\
\hline $\mathrm{PHI}$ & Serum & $\begin{array}{l}\text { Combines total, free and }(-2) \\
\text { proPSA }\end{array}$ & 0.703 & 80 & 45 & [35] \\
\hline 4 Kscore $^{\circledR}$ & Serum & $\begin{array}{l}\text { Consists of total PSA, free } \\
\text { PSA, intact PSA and KLK2 }\end{array}$ & 0.711 & - & - & [36] \\
\hline ConfirmMDx ${ }^{\circledast}$ & $\begin{array}{l}\text { Prostate } \\
\text { biopsy tissue }\end{array}$ & $\begin{array}{l}\text { Measures the degree of } \\
\text { methylation of GSTP1, APC } \\
\text { and RASSF1 }\end{array}$ & - & 68 & 64 & [37] \\
\hline
\end{tabular}

PSA values improved the classification of PCa risk and mortality.

Due to the conflicting evidence with regards to PSAV and PSADT as a screening tool for PCa diagnosis, several expert consensus recommendations have been developed [49]. These include: first, high PSAV is not an indication for biopsy; second, men with a low PSA but a high PSAV should have another PSA drawn at a shorter time interval; third, men with an indication for biopsy should be biopsied regardless of PSAV; fourth, changes in PSA after negative biopsy findings do not indicate the need for repeat biopsy, and lastly, PSA monitoring over time can aid in clinical decisionmaking about biopsy but judgment should ultimately be informed by the clinical context.

\section{PCA3}

PCA3 is a noncoding RNA with expression confined to the prostate, which is highly overexpressed in $95 \%$ of $\mathrm{PCa}$ cases compared with benign prostatic tissue [50]. Some men, however, may have a very high PCA3, but no evidence of malignancy [51]. It is commercially available as a diagnostic test that quantitatively detects PCA3 RNA expression in the urine and prostatic fluid after prostatic massage with a score higher than 35 in the urine correlating with an average sensitivity and specificity of 66 and $76 \%$, respectively, for the diagnosis of $\mathrm{PCa}$ (compared with a sensitivity of $65 \%$ and specificity of $47 \%$ for PSA alone) [35]. Elevated PCA3 can also increase the probability of a positive repeat prostate biopsy in men with one or two prior negative biopsies, and it is the US FDA approved for this indication [52]. As such, it may play a complimentary role to PSA alone in PCa screening.

\section{Prostate health index}

The Beckman Coulter Prostate Health Index (PHI) combines total, free and [-2]proPSA into a single score to improve PCa detection [53]. As a component of free PSA, [-2]proPSA is more specific for PCa than total or free PSA alone [36,54]. Catalona et al. evaluated the PHI in a prospective, multi-institutional trial of 892 men with a PSA between 2 and $10 \mathrm{ng} / \mathrm{ml}$ and a negative digital rectal examination (DRE) [55]. The predictive ability of PHI to diagnose $\mathrm{PCa}(\mathrm{AUC}=0.703)$ exceeded that of serum PSA (AUC $=0.525)$, free PSA (AUC $=0.615)$, p2PSA (the primary form in PCa tissue) $(\mathrm{AUC}=0.557)$ or percent-free PSA (AUC $=0.648)$. PHI also performed better than percent-free PSA in its ability to discriminate PCa with a Gleason score (GS) $\geq 4+3=7$ versus lower grade PCa or benign histology (AUC $=0.724$ vs 0.670 ).

Loeb et al. also externally validated the $\mathrm{PHI}$ in a multicenter prospective trial of 658 men aged $\geq 50$ years with a PSA of $4-10 \mathrm{ng} / \mathrm{ml}$ and normal DRE who underwent prostate biopsy [56]. Based on Epstein criteria, the PHI was able to detect clinically significant disease (AUC $=0.698)$ with more accuracy than percentfree PSA (AUC $=0.654),[-2]$ proPSA $(A U C=0.550)$ or PSA (AUC $=0.549$ ) alone, suggesting its use to reduce prostate biopsies and the overdiagnosis of indolent disease.

\section{Kallikrein panel}

Another promising serum-based biomarker is the kallikrein panel (4k-panel) (OPKO Health Inc., FL, USA) that consists of total PSA, free PSA, intact PSA and human kallikrein-related peptidase 2 (KLK2) [57]. This prostate '4Kscore ${ }^{\circledR}$ ' was shown by Vickers et al. to improve the predictive accuracy of PCa detection over PSA alone (AUC: 0.711 vs 0.585 ) with a reduction in the biopsy rate by 362 for every 1000 men with elevated PSA [58]. Similar results have been seen in externally validated populations in France and The Netherlands with an improvement in the detection of high-grade cancers (AUC increased from 0.77 to 0.87 
and 0.76 to 0.87 , respectively) [59,60]. When comparing the $4 \mathrm{k}$-panel to the PHI, both similarly improved discrimination when predicting both PCa and high-grade $\mathrm{PCa}$, reducing the number of unnecessary biopsies compared with PSA alone [61]. The 4k-panel has also been shown to enhance the prediction of lethal PCa associated with metastasis compared with PSA alone, providing an additional use as a screening tool for men with elevated PSA [62]. In patients with elevated PSA (>3 ng/ml), low percent-free PSA or suspicious DRE, the $4 \mathrm{k}$-panel of kallikrein markers improved discrimination over age and PSA for high-grade cancer (GS $\geq 7$; $\mathrm{AUC}=0.77$ vs $0.720 ; \mathrm{p}=0.002)$, reducing the number of biopsies by 236 per 1000 to detect 195 of 208 high-grade cancers [63].

\section{TMPRSS2:ERG fusion}

\section{\& $\beta$-microseminoprotein}

Tomlins et al. recognized one of the most frequent gene-specific alterations in $\mathrm{PCa}$ represented by a fusion between the TMPRSS2 gene and the v-ets avian erythroblastosis virus $E R G$ gene [64]. Detection of the TMPRSS2: ERG fusion in the urine after prostatic massage has been reported to yield more than $90 \%$ specificity and $94 \%$ positive predictive value (PPV) for $\mathrm{PCa}$ detection [65]. The sensitivity of this assay, however, is low since $40-50 \%$ of prostate tumors carry this fusion, but it can be improved in combination with PCA3. Urinary detection of PCA3 and TMPRSS2:ERG with serum PSA levels has also been reported to improve $\mathrm{PCa}$ screening performance compared with PSA alone [66]. Other biomarkers in an active area of research include urinary concentrations of $\beta$-microseminoprotein, whose levels are decreased in PCa compared with normal prostate tissue [67]. Decreased urinary levels of $\beta$-microseminoprotein have been shown to improve PCa diagnosis over urinary PSA but not serum PSA, so further testing is required to demonstrate any potential utility of this test.

\section{DNA methylation markers}

Hypermethylation of $\mathrm{CpG}$ islands in the promoter regions of cancer-associated genes is linked to PCa [68]. Three of these genes include GSTP1 [68], which is involved in DNA detoxification; $A P C$, which is involved in cell apoptosis, migration and adhesions [69]; and RSSF1, which is involved in cell cycle regulation [70]. A recent meta-analysis concluded that GSTP1 methylation occurs in up to $90 \%$ of PCa cases (on both tissue biopsy and RP specimens), while it is only seen in 5\% of noncancerous controls [37]. GSTP1 is also the most widely reported hypermethylated gene in PCa [71]. Since DNA hypermethylation of key genes occurs early during oncogenesis, it is ideally suited for
PCa detection [72]. Due to the concept of epigenetic field effect in prostate carcinogenesis [73], investigators have evaluated whether biopsy samples taken with negative pathology findings may produce a positive molecular result since genetic alterations occur in histopathologically nonmalignant tissue that is contiguous with cancerous tissue [74].

In the MATLOC study, Stewart et al. determined the degree of methylation of GSTP1, APC and RASSF1 to detect $\mathrm{PCa}$ in initial histopathologically negative biopsy samples from men who were subsequently rebiopsied [75]. This epigenetic assay resulted in a negative predictive value (NPV) of 90\% (compared with $70 \%$ for histopathology alone), and it was an independent predictor of $\mathrm{PCa}$ detection up to 30 months before repeat biopsy. In the follow-up DOCUMENT study, this epigenetic test was externally validated in 350 subjects with an initial negative prostate biopsy across five urological centers in the USA [76]. It resulted in a NPV of $88 \%$ and again was an independent predictor of $\mathrm{PCa}$ detection on multivariate analysis after correcting for age, PSA, DRE, histopathological characteristics on first biopsy and race. Negative findings of this assay, therefore, could be used to decrease concern about unsampled cancer and avoid unnecessary repeat prostate biopsies. The impact of this epigenetic test (commercially available as ConfirmMDx ${ }^{\circledR}[\mathrm{MDx}-$ Health, CA, USA]) on rebiopsy rates was recently surveyed at five centers, and among 138 patients with a negative assay, only six patients (4\%) underwent repeat biopsy [77].

\section{Biomarkers in PCa prognosis \\ PSA kinetics \& PSA density}

The role of PSA kinetics (PSAV and PSADT) as a tool for PCa prognosis has been extensively studied and is still highly ambiguous as a predictive factor in disease aggressiveness [78]. Khatami et al. and Soloway et al. both reported that preoperative PSADT was a statistically significant predictor of disease progression and PSA relapse after RP [79,80]. Ross et al., however, reported a $35 \%$ rate of disease progression on repeat biopsy in an AS program at median follow-up of 2.9 years, and neither PSAV nor PSADT was a significant predictor of progression on univariate analysis [28]. Whitson et al. similarly revealed that PSADT was not significantly associated with risk of biopsy disease progression (grade or volume increase) [81]. Iremashvili et al. reported that PSAV significantly predicted tumor progression in certain subgroups, including men undergoing their fourth or later surveillance biopsy, but in the overall population, there was no significant increase in the predictive accuracy compared with PSA alone [82]. Additionally, PSADT 
was not associated with biopsy progression in any group in this study. Conversely, San Francisco et al. found that PSAV along with PSADT and family history was highly predictive of disease progression ( $\geq 3$ positive cores, GS $\geq 7$ or $>50 \%$ core volume) [83]. Finally, Patel et al. examined PSAV risk count (number of times PSAV exceeded $0.4 \mathrm{ng} / \mathrm{ml}$ per year), which outperformed standard PSAV as a predictor of disease progression on AS [84]. The 5-year probability of biopsy reclassification ( $G S>6, \geq 3$ positive cores, $>50 \%$ core volume) was 9.7, 18.7 and $39.5 \%$, respectively, with risk counts of 0,1 and $2(\mathrm{p}<0.01)$, respectively, and men with a risk count higher than 1 had a four-times greater risk of reclassification on multivariate analysis. For men with a risk count of $0-1$, the NPV for reclassification the following year was $91 \%$, providing a potential means to reduce invasive biopsies. Use of PSA kinetics as a stand-alone test to determine PCa progression, such as in AS programs, yields highly mixed results, but it could be used to trigger further diagnostic intervention such as MRI or saturation biopsy.

PSA density (PSAD), on the other hand, may predict GS upgrading in AS protocols for low-risk disease [85]. Barayan et al. and Dall'Era et al. both reported that a PSAD $>0.15 \mathrm{ng} / \mathrm{ml}$ per cubic centimeter at diagnosis was an important predictor for disease progression and increasing GS on repeat biopsy [86,87]. Venkitaraman et al. also showed that PSAD was a predictor of histologic disease progression (primary GS $\geq 4,>50 \%$ positive cores or GS increase from $\leq 6$ to $\geq 7$ ) on univariate analysis, but it did not reach statistical significance on multivariate analysis $(p=0.069)$ [88]. A limitation of PSAD, however, is inaccuracy of assessing prostate volume on transrectal ultrasound [89], and loss of significance in the face of new PSA-based tests such as proPSA and PSAV risk count [90]. Tosoian et al. found percent [-2]proPSA and PHI provided the greatest predictive accuracy (over PSAD) for reclassification to highgrade cancer in patients on AS [91], and Hirama et al. showed baseline [-2] proPSA and PHI (but not PSAD) predicted pathological reclassification at 1 year in patients with low-risk disease [92].

Current recommendations suggest making treatment decisions such as AS versus surgery versus XRT or adjuvant therapy, irrespective of PSAV, PSADT or PSAD, using established prediction models based on disease stage, grade and total PSA. PSAV, however, at the time of recurrence should be entered into prognostic models to aid patient counseling since PSA changes after treatment for advanced disease can help indicate therapeutic effectiveness with a rising PSA on treatment indicating likely nonresponse.

\section{PCA3 \& TMPRSS2:ERG fusion}

The data on PCA3 and PCa prognosis are limited. Tosoian et al. examined urinary PCA3 in men with very low-risk PCa prospectively in an AS cohort and found that PCA3 had poor discrimination $(\mathrm{AUC}=0.589)$ and was not significantly associated with short-term biopsy progression on multivariate analysis after accounting for age and diagnosis date $(\mathrm{p}=0.15)$ [93]. Newer reports, however, have found a significant association between elevated PCA3 and GS $\geq 7$ on subsequent prostate biopsy $(\mathrm{p}=0.02)$ as well as an improved overall detection of $\mathrm{PCa}(82.1 \%$ sensitivity and $79.3 \%$ specificity) [94].

Although gene fusions, specifically E26 transformation-specific (ETS) fusions such as the TMPRSS2:ERG translocation, have been associated with the early onset of $\mathrm{PCa}$, its clinical utility as a prognostic tool is still unclear. Nam et al. reported that the expression of the TMPRSS2:ERG gene fusion on PCR of prostate specimens was independently predictive of biochemical recurrence (BCR) after RP (HR: 8.6) [95] as well as disease progression in a small, selected cohort of intermediate-risk patients with GS 7 adenocarcinoma [96]. In contrast, Saramaki et al. demonstrated lower BCR risk after RP associated with the TMPRSS2:ERG gene fusion based on FISH [97]. Steurer et al. found that the TMPRSS2:ERG gene fusion was associated with lowgrade tumors in younger patients but not with overall outcomes [98], and Dal Pra et al. demonstrated no association between the TMPRSS2:ERG gene fusion and BCR in almost 250 men treated with intensity-modulated radiation therapy (IMRT) [99]. Gopalan et al., Hoogland et al. and Minner et al. similarly found no association between the TMPRSS2:ERG gene fusion and BCR or local recurrence after RP [100-102]. A large meta-analysis of 5074 men following RP also found no significant association between the TMPRSS2:ERG gene fusion and BCR or disease progression [103]. Further analysis beyond the overall expression of the gene fusion, however, can provide more significant prognostic value. FitzGerald $e t$ al. did not observe an association between the TMPRSS2:ERG gene fusion and overall clinical outcomes in PCa patients, but men with increased copy numbers showed poorer survival [104]. Additionally, Boormans et al. reported that the TMPRSS2:ERG exon 0 gene fusion was associated with a lower risk of BCR compared with the exon 1 fusion [105].

Presence of the TMPRSS2:ERG gene fusion may play more of a role in predicting outcomes in AS populations or watchful waiting (WW) cohorts undergoing palliative transurethral resection of the prostate (TURP). Berg et al. evaluated 265 men on AS and reported that expression of TMPRSS2:ERG 
gene fusion in biopsy specimens was independently associated with progression risk (58.6 vs $21.7 \%$; HR: 2.45) [106]. Lin et al. found that on univariate analysis, urinary PCA3 and TMPRSS2:ERG expression were significantly associated with higher volume disease and higher grade disease, but this was not significant with biopsy reclassification on multivariate analysis [107].

Attard et al. and Hagglof et al. both showed that the TMPRSS2:ERG gene fusion was independently predictive of CSS and overall survival (OS) based on both FISH and immunohistochemistry (IHC) in metastatic patients undergoing palliative TURP [108,109], and this was similarly reproduced by Demichelis et al. and Qi et al. [110,111]. It was thought, therefore, that TMPRSS2:ERG expression could be related to response to androgen deprivation therapy (ADT). Boormans et al., however, found no association between the TMPRSS2:ERG gene fusion with ADT response in PCa patients with lymph node metastases [112]. Similarly, Leinonen et al. found no association between the TMPRSS2:ERG gene fusion and disease progression in ADT-treated patients [113].

Although the TMPRSS2:ERG gene fusion alone has little prognostic impact, its predictive value improves in combination with other investigative markers including other gene-expression panels [114-116]. As result, its clinical utility remains in flux.

\section{Copy number variations}

Gains or losses of areas of somatic DNA (i.e., NKX3.1) can have carcinogenic consequences, and $\mathrm{PCa}$ overall is characterized by loss of genomic material [117]. Specific gains or deletions as well as the overall burden of copy number variations (CNVs) may have a prognostic role in PCa pathogenesis.

Tsuchiya et al. investigated specific chromosome 8 abnormalities, and loss of 8 p22 was associated with an increased risk of BCR and metastatic progression [118]. Loss of $8 \mathrm{p} 22$ in prostate biopsy specimens was also associated with $\mathrm{PCa}$ radioresistance after image-guided XRT with increased positive biopsies posttreatment [119]. Liu et al. studied the 20 most significant CNVs (15 deletions, five amplifications) in two RP cohorts and found that gain of $M Y C$ and deletion of PTEN were significantly associated with PCa-related death (after controlling for pathological stage, GS and initial PSA level) [120]. CNVs of $M Y C$ and PTEN were similarly found to be prognostic factors for disease relapse in $\mathrm{PCa}$ patients undergoing XRT (HR: 2.58) [121].

Paris et al. found that specific DNA-based biomarkers were associated with advanced disease stage (loss at 8p23.2) and were found to be predictive of postoperative recurrence (gain at 11q13.1) independent of tumor stage and grade [122]. The authors also suggest that a combined set of 39 loci termed the Genomic Evaluators of Metastatic Prostate Cancer (GEMCaP) is associated with PCa recurrence and metastasis. Subsequently, the GEMCaP was demonstrated to offer additional prognostic information above the Kattan nomogram for disease recurrence in high-risk node-negative $\mathrm{PC}$ a cases after RP (accuracy $=78 \%$ of nomogram + GEMCaP vs $65 \%$ of nomogram alone) [123].

As noted from the above studies, CNV analysis may have a prognostic role in PCa patients, but standardization of methods and additional validations studies are required before clinical applications can be planned.

\section{PTEN}

One of the most frequently deleted genes in human cancer is a PTEN deletion on chromosome 10, which dephosphorylates lipid-signaling intermediates resulting in deactivation of PI3K signaling, thus controlling cell proliferation and growth [124]. Saal et al. initially correlated PTEN loss with poor outcomes in a variety of malignancies [125]. The prognostic value of PTEN deletion in PCa has subsequently been investigated in several studies. Leinonen $e t$ al. demonstrated a higher frequency of PTEN loss in more advanced cases (castrate-resistant PCa [CRPC] compared with localized disease in RP cases) and that PTEN loss was associated with shorter progression-free survival (PFS) in ERG-positive tumors [126]. Yoshimoto et al. reported that homozygous PTEN deletion in prostate specimens was independently associated with BCR risk after RP and was clearly associated with TMPRSS2:ERG gene expression [127]. Furthermore, PTEN loss at the time of RP correlated with clinical parameters of more advanced disease, such as extraprostatic extension and seminal vesicle invasion [128]. Krohn et al. examined over $4700 \mathrm{RP}$ specimens and 57 CRPC cases, and the authors concluded that PTEN loss was independently associated with adverse clinicopathological features and was predictive of BCR and worse PFS after surgery [129]. ERG status, however, did not affect the predictive value of PTEN loss. Reid et al. showed that PTEN loss without TMPRSS2:ERG gene fusion on FISH and IHC was associated with worse CSS in castrate-sensitive cases. This is contrast to prior studies linking PTEN loss and positive TMPRSS2:ERG gene expression with worse outcomes [130]. Finally, McCall et al. compared PTEN status in both castration-sensitive and CRPC, noting that PTEN loss was independently associated with worse CSS but only in castrate-sensitive cases [131]. PTEN-negative tumors, however, have been associated with shorter survival in CRPC in the postchemotherapy setting during treatment with abiraterone [132]. 
Other markers have been tested in combination with PTEN loss for prognostic information including tumor protein $p 27$ gene loss, $H O-1$ overexpression and $H E R 2 / 3$ overexpression. Halvorsen et al. reported that combined loss of PTEN and $p 27$ expression defined a group of tumors based on RP specimens associated with increased tumor diameter, seminal vesicle invasion, increased pathological stage and elevated tumor cell proliferation detected by antigen KI-67 [133]. Loss of PTEN and $p 27$ expression was an independent predictor of time to BCR and clinical recurrence. Li et al. assessed the occurrence of both HO-1 expression and PTEN deletion in men with localized and CRPC [134]. HO-1 epithelial expression was statistically different between benign prostate tissue, high-grade PIN, localized PCa and CRPC ( $\mathrm{p}<0.001)$. Although neither HO-1 overexpression nor PTEN deletion alone in localized PCa was independently associated with PSA relapse, the combined status of both markers correlated with disease progression $(\mathrm{p}=0.01)$. Inhibition of $H O-1$ also strongly reduced cell growth and invasion in vitro and inhibited tumor growth and lung metastasis formation in mouse models. Finally, Ahmad et al. showed that patients who developed prostate tumors with low levels of PTEN and high levels of HER2/3 have a poor prognosis [135]. These tumors, however, responded favorably to MAPK enzyme (MEK) inhibition by restoring the PTEN loss.

Loss of the PTEN gene and protein also shows promise as a prognostic biomarker in PCa patients on AS. PTEN status on RP specimens assessed by FISH has shown to be an independent predictor for preoperative PSA and GS with PTEN homozygous deletion associated with worse disease stage [136]. Tumors with PTEN protein loss were also more likely to be upgraded at the time of RP than those without loss, even after adjusting for age, preoperative PSA, clinical stage and race (OR: 3.04; $\mathrm{p}=0.035)$ [137]. PTEN loss in Gleason 6 biopsy specimens identified a unique subset of prostate tumors at increased risk of upgrading at the time of RP. These data provide evidence that the assessment of PTEN status can improve Gleason accuracy and highlight a path toward the clinical use of molecular markers to augment pathologic grading.

\section{Peripheral blood \& circulating tumor cells}

In addition to genetic information, peripheral blood is a potential source for genomic tumor characterization using free circulating nucleic acids, whole blood transcripts or circulating tumor cells (CTCs). Bastian et al. reported an increasing quantity of circulating cell-free DNA independently associated with the risk of BCR after RP [138]. Ross et al. examined a six-gene panel (consisting of ABL2, SEMA4D, ITGAL, C1QA, TIMP1 and CDKN1A) in CRPC patients with significantly improved prognostic value compared with a clinical model alone (AUC $=0.90$ vs $0.65 ; \mathrm{p}=0.0067$ ) [139], and Olmos et al. identified a nine-gene signature analyzed from blood messenger RNA (mRNA) in CRPC patients that was independently associated with worse OS [140]. Specific circulating miRNAs found not only in tumor tissue but also in the plasma of PCa patients, such as miRNA-375 and miRNA-141, have also been shown to be associated with advanced disease [141].

Danila et al. investigated the expression of five genes frequently detected in PCa cells $(K L K 3, K L K 2$, HOXB13, GRHL2 and FOXA1) from whole blood transcripts as well as detection of CTCs [142]. Both an unfavorable CTC count (five or more cells) and detection of two or more gene transcripts had similar significant prognostic value for the risk of PCa-related death, and when combined, additional prognostic value was demonstrated. Additionally, KLK3, PCA3 and TMPRSS2:ERG mRNA could be detected in the peripheral blood of CRPC patients but not in healthy controls [143]. Decreased expression levels of these genes, however, were noted after docetaxel treatment, suggesting a potential role for treatment monitoring. Finally, Scher et al. demonstrated that a biomarker panel using CTC count and lactate dehydrogenase (LDH) was a surrogate for survival at the individual patient level in the Phase III trial of abiraterone plus prednisone versus prednisone alone (COU-AA-301) for patients with CRPC [144]. We suspect that peripheral blood markers and CTCs will continue to gain traction for use in future clinical studies as they can be easily collected with minimal patient morbidity.

\section{Genetic panels in PCa prognosis}

Multiple genetic markers are often necessary to provide enough prognostic information for clinical decision-making versus any single genetic abnormality alone. Panels evaluating the differential expression of multiple genes are ideally created using knowledge of well-known carcinogenic pathways in PCa [145]. There is a risk of chance associations due to the number of genetic mutations associated with prostate malignancy, but blinded marker analysis and external validation is essential before any clinical application can be considered [146]. Additionally, the biomarkers in the panel have to provide additional independent predictive ability above and beyond standard clinical and pathological characteristics. Recommendations for reporting the clinical utility of biomarkers in oncology are, therefore, essential to follow [147].

Three commercially available RNA-based genetic panels that have been externally validated in the PCa population and are currently utilized in clinical prac- 
tice are listed in Table 3. It is important to note that there is virtually no overlap between these panels even though they include a total of 85 genes. Additionally, there are no comparative or prospective studies evaluating these expression panels head-to-head in the same patient cohort. The commercial assays may also be less helpful because of the difficulties of using them effectively on the variable amount of tumor present at first diagnosis in needle cores.

Lalonde et al. also recently reported on a panel of DNA-based indices in 126 low-to-intermediate-risk PCa patients in order to develop four genomic subtypes for $\mathrm{PCa}$ that were prognostic for relapse after both XRT (HR: 4.5; AUC = 0.70) and RP (HR: $4.0 ; \mathrm{AUC}=0.57)$ and whose effect was magnified by intratumoral hypoxia (HR: 3.8; AUC $=0.67$ ) [150]. This novel 100-loci DNA signature was subsequently externally validated in two independent cohorts of RP specimens from low-risk to high-risk patients, and it accurately classified treatment outcomes and identified patients who were most likely to fail treatment within 18 months (HR: 2.9; $\mathrm{AUC}=0.68 ; \mathrm{p}=0.004$ ).

\section{Prolaris $^{\circledR}$}

Cuzick et al. identified a 46-gene-expression model (31 cell-cycle progression genes and 15 housekeeping genes) via quantitative PCR on RNA extracted from $\mathrm{PCa}$ tumor samples [145]. This cell cycle progression (CCP) score was evaluated retrospectively in a cohort of RP and TURP patients managed conservatively. The primary end point was BCR in the RP group and OS in the TURP group. The CCP score was an independent predictor of BCR for RP patients on univariate (HR: 1.89) and multivariate (HR: 1.77) analysis, and it was also strongly associated with time to death from PCa for TURP patients on univariate (HR: 2.92) and multivariate (HR: 2.57) analysis. CCP was also found to be a stronger prognostic factor than any other measured variable including PSA.

This gene panel (commercially available as the Prolaris test [Myriad Genetics, UT, USA]) was subse- quently externally validated using biopsy and TURP specimens in 349 patients managed conservatively with the primary end point being PCa-specific mortality [151]. The CCP score was again independently associated with PCa-related death on univariate (HR: 2.02) and multivariate (HR: 1.65) analysis with GS and PSA providing significant additional contributions.

The Prolaris test has also been externally validated in RP studies. Cooperberg et al. analyzed 413 men who underwent RP and determined whether the CCP score (analyzed on RP tissue) could predict BCR (defined as two PSA levels $\geq 0.2 \mathrm{ng} / \mathrm{ml}$ ) [148]. The CCP score was also assessed for independent prognostic utility beyond a stand postoperative risk assessment instrument such as the Cancer of the Prostate Risk Assessment post-Surgical (CAPRA-S) score, which uses pathological data from RP to predict $\mathrm{PCa}$ recurrence and mortality [152] and has been externally validated in over 2500 men across multiple institutions (concordance index $[c$-index $]=0.72$ for $\mathrm{BCR}$ and 0.85 for PCa-specific mortality) [149]. CCP was independently predictive of BCR after RP on univariate (HR: 2.1) and multivariate (HR: 1.7) analysis after adjusting for the CAPRA-S score. CCP also was able to substratify patients with low clinical risk as defined by CAPRA-S $\leq 2$ (HR: 2.3). Combining the CCP and CAPRA-S scores improved the c-index for both the overall cohort and the low-risk subset, suggesting that the combined score outperformed both individual scores in clinical decision-making (c-index $=0.77$ for genetic + clinical model vs 0.73 for clinical model alone).

Bishoff $e t$ al. also evaluated the CCP score as a predictor of BCR and metastatic disease based on pre-RP biopsy tissue in 582 men treated with RP for clinical localized PCa [153]. CCP was the strongest predictor of BCR on univariate (HR: 1.6) and multivariate (HR: 1.47) analysis, and it was also the strongest predictor of metastatic disease on univariate (HR: 5.35) and multivariate (HR: 4.19) analysis after adjusting for other clinical variables.

Table 3. Commercially available RNA-based gene panels utilized in clinical practice for prostate cancer prognosis.

\begin{tabular}{|llllll|}
\hline Panel & Company & Tissue type & $\begin{array}{l}\text { Number of } \\
\text { genes }\end{array}$ & End point & Ref. \\
Prolaris & Myriad Genetics & $\begin{array}{l}\text { Radical prostatectomy, } \\
\text { prostate biopsy }\end{array}$ & 31 & BCR, DSS, MFS & {$[140]$} \\
Oncotype DX ${ }^{\circledast}$ & $\begin{array}{l}\text { Genomic Health } \\
\text { Inc. }\end{array}$ & $\begin{array}{l}\text { Radical prostatectomy, } \\
\text { prostate biopsy }\end{array}$ & 17 & $\begin{array}{l}\text { BCR, adverse RP } \\
\text { pathology, MFS }\end{array}$ & {$[148]$} \\
Decipher & $\begin{array}{l}\text { GenomeDX } \\
\text { Biosciences }\end{array}$ & Radical prostatectomy & 22 & BCR, DSS, MFS & [149] \\
\hline BCR: Biochemical recurrence; DSS: Disease-specific survival; MFS: Metastasis-free survival; RP: Radical prostatectomy. & \\
\hline
\end{tabular}


Freedland et al. tested the prognostic utility of the Prolaris test in 141 PCa patients treated with external beam radiation therapy (EBRT) as their primary curative therapy using pretreatment diagnostic prostate biopsy specimens to predict BCR. BCR was defined using the Pheonix definition, and half of the cohort was African-American. The BCR rate was $13 \%(\mathrm{n}=19)$, and the CCP score significantly predicted BCR on univariate $(\mathrm{p}=0.0017)$ and multivariate $(\mathrm{p}=0.034)$ analysis accounting for GS, PSA, percent-positive cores and use of ADT. The CCP score also was associated with PCa-specific mortality at 10 years $(\mathrm{p}=0.013)$.

The impact of the CCP score was prospectively analyzed based on physician-completed surveys regarding PCa treatment recommendations in 305 men before and after they received the Prolaris test results [154]. Clinicians also rated the influence of the test on treatment decisions. Surprisingly, the Prolaris test changed physician treatment recommendations in $65 \%$ of cases, and in $40 \%$ there was a reduction in treatment burden (interventional treatment changed to noninterventional). The long-term impact of these changes on patient outcomes, however, is not known.

\section{Oncotype DX ${ }^{\circledast}$}

Klein et al. identified 17 genes through PCR based on $441 \mathrm{RP}$ specimens from low- to intermediaterisk patients representing multiple biological pathways in PCa out of 732 candidate genes (288 predicted clinical recurrence and tumor multifocality, and 198 were predictive of aggressive disease after adjustment for PSA, GS and clinical stage) [155]. This 17-gene-expression panel was further confirmed in 167 pre-RP biopsy specimens to create a multigene, expression-based signature called the Genomic Prostate Score (GPS). This algorithm was subsequently internally validated in 395 needle biopsies from contemporary patients who were candidates for AS to determine its ability to predict clinical recurrence, PCa-related death and adverse pathological features at the time of RP. In this validation study, the GPS predicted high-grade (Gleason $\geq 4+3$; OR: 2.3 ) and high-stage (pT3 or higher; OR: 1.9) disease on RP specimens after controlling for established clinical factors (age, PSA, clinical stage, biopsy GS), and this was similarly true after inclusion of a clinical risk model (i.e., CAPRA-S; OR: 2.1).

This test (commercially available as the Oncotype DX test [Genomic Health, CA, USA]) was subsequently externally validated by Cullen et al. in 431 prostate biopsies from men with very low-, low- or intermediate-risk PCa based on National Comprehensive Cancer Network (NCCN) guidelines [156]. GPS scores were correlated with BCR, adverse pathology (primary Gleason patter 4 or any pattern 5, pT3 disease) and metastatic recurrence. GPS scores did not vary across race with similar distributions of results, and it was an independent predictor of BCR (HR: 2.7), time to metastases (HR: 3.8) and adverse pathology (OR: 3.3) after adjusting for the NCCN risk group. The Oncotype DX test performed on a patient's original prostate needle biopsy, therefore, may predict the aggressiveness of $\mathrm{PCa}$ and help men make decisions regarding immediate treatment versus AS.

\section{Decipher $^{\circledast}$}

Erho et al. presented a case-control study that analyzed a 22-gene-expression signature in men with early clinical metastasis after rising PSA to predict survival after RP [157]. The 22-gene panel (based on the primary tumor in the RP specimen) was the only significant prognostic factor for early metastasis and $\mathrm{PCa}$-specific death on multivariable analysis, and it had a good correlation with DSS on internal validation (AUC $=0.75$ ). Patients with higher scores experienced earlier death from $\mathrm{PCa}$ and reduced OS, suggesting its use as an identifier of aggressive prostatic malignancy.

This 22-gene panel (commercially available as the Decipher test [GenomeDX Biosciences, BC, USA]) was externally validated in multiple studies. Cooperberg et al. compared the CAPRA-S score and the Decipher genomic classifier (GC) as a predictor of $\mathrm{PCa}$-specific mortality in 185 men at high risk of recurrence (PSA $>20$, GS $\geq 8$, stage pT3b) after RP of whom 25 experienced $\mathrm{PCa}$-associated death [158]. The c-indices for CAPRA-S and Decipher GC were 0.75 and 0.78, respectively, and Decipher GC reclassified many men stratified to high-risk based on the CAPRA-S score $\geq 6$. Both high CAPRA-S and Decipher GC scores were independently predictive of PCa-specific mortality (HR: 2.36 and 11.26, respectively) with a cumulative incidence of PCa-related death of $45 \%$ at 10 years. This suggests that integration of genomic and clinical classifiers may enable better identification of post-RP patients at high-risk for death who should be considered for more aggressive secondary therapies and clinical trials.

Karnes et al. also evaluated 219 men at high risk of recurrence (PSA $>20, G S \geq 8$, stage $\mathrm{pT} 3 \mathrm{~b}$ ) with the Decipher test based on the genomic information from the primary tumor in the RP specimen [159]. The Decipher GC AUC was 0.79 for predicting 5-year metastasis after RP, which exceeded that of clinical models. The Decipher GC was also the predominant predictor of metastasis 5 years after RP on multivariate analysis with a cumulative incidence of $2.4,6.0$ and $22.5 \%$ in patients with low (60\%), intermediate (21\%) and high $(19 \%)$ scores, respectively $(\mathrm{p}<0.001)$. 
In another study, 85 clinically high-risk RP patients who developed BCR after surgery were analyzed using the Decipher GC as a predictor of metastatic disease progression [160]. The AUC of Decipher GC for predicting metastasis after BCR was 0.82 compared with 0.64 for GS, 0.69 for PSADT and 0.52 for time to $\mathrm{BCR}$. It was the only variable associated with metastatic progression on multivariate analysis $(\mathrm{p}=0.003)$, and it performed superiorly to models solely based on clinicopathological features (i.e., CAPRA-S).

Finally, studies have also evaluated the utility of Decipher GC to predict which men would benefit from adjuvant XRT therapy as well as to forecast outcomes after postoperative XRT following RP. Den et al. calculated Decipher GC scores from the primary tumor specimens of 188 patients with $\mathrm{pT} 3$ or margin-positive $\mathrm{PCa}$ after RP who received post-RP XRT [161]. The primary end point was clinical metastasis, and the prognostic accuracy of Decipher GC was compared with other routine clinical and pathological features. Decipher GC and pre-RP PSA were both independent predictors of metastasis $(\mathrm{p}<0.01)$ with a cumulative incidence at 5 years of 0,9 and $29 \%$ for low, average and high GC scores. For patients with low GC scores, there was no difference in the cumulative incidence of metastasis comparing patients who received adjuvant vs salvage XRT ( $\mathrm{p}=0.79$ ), but for patients with high GC scores, the cumulative incidence of metastasis at 5 years was significantly lower in patients who received adjuvant vs salvage XRT (6 vs $23 \%$; $\mathrm{p}<0.01$ ). These findings suggest that patients with high Decipher GC scores may benefit from adjuvant XRT, while patients with low Decipher GC scores are best treated with salvage XRT.

This same group also reported on the ability of the Decipher GC score to predict BCR and distant metastasis in men receiving XRT after RP [162]. The authors evaluated $139 \mathrm{PCa}$ patients with $\mathrm{pT} 3$ or positive margins after RP who received postoperative XRT (both adjuvant and salvage) and found that the addition of Decipher GC improved the AUC of a clinical model (i.e., Stephenson model) from 0.70 to 0.78 and from 0.70 to 0.80 as a predictor of BCR and distant metastasis, respectively. On multivariate analysis, high Decipher GC scores were independent predictors of BCR (HR: 8.1) and distant metastasis (HR: 14.3) with a cumulative incidence of 21, 48 and 81\% for BCR and 0, 12 and 17\% for distant metastasis for low, intermediate and high GC scores, respectively. The Decipher GC, therefore, may be predictive of oncological outcomes after post-RP XRT and improve decision-making in high-risk cases.

\section{Biomarkers in PCa response to treatment}

Genetic markers that can predict response or resistance to treatment could be valuable in the selection of a therapy with the greatest likelihood of efficacy in an individual patient. They may also categorize patients into clinical trials based on the presumed likelihood of response to the tested agents.

It is well known that ADT is first-line therapy for metastatic PCa. Inherited genetic factors, however, may account for variability in response to ADT. Ross et al. identified three polymorphisms (CYP19A1, HSD3B1 and $H S D 17 B 4$ ) independently associated with longer time to progression (TTP) during ADT on multivariate analysis [163]. Patients carrying more than one of these polymorphisms demonstrated a better response to ADT than patients carrying none $(\mathrm{p}<0.0001)$. The SLCO1B3 polymorphism, on the other hand, was found to be associated with a shorter time to androgen independence in PCa patients due to its enhanced effect on testosterone import [164]. Yang et al. also identified three SNPs in SLCO2B1 associated with shorter TTP on ADT. Individuals carrying the SLCO1B3 and $S L C O 2 B 1$ genotype allowed for more efficient import of androgen and enhanced cell growth associated with a median 2-year worse TTP on ADT [165].

Although ADT remains first-line treatment for metastatic PCa, predicting the response of CRPC to various novel agents may have added value. Theoretically, tumors with AR amplification or overexpression would be expected to respond well to abiraterone, which further decreases circulating androgens. Conversely, tumors with AR mutations leading to promiscuity to nonandrogen substrates or loss of AR expression would be expected to respond well to enzalutamide, which prevents AR nuclear import. CRPC mediated through active splice variants lacking the ligand-binding domain at the carboxy-terminal of the AR protein might require novel agents targeting the amino-terminal of the protein [166]. Multiple markers have also been implicated in taxane resistance in CRPC, including elevated class III $\beta$-tubulin expression $[167,168]$. These markers, however, have yet to be prospectively validated.

Peripheral blood genetic information may be useful to predict therapeutic response in CRPC. Pretherapy CTC counts have been demonstrated to predict response to therapy, and a decrease in the number of CTCs after therapy had a greater predictive value than the classic 50\% PSA decrease [169]. This was observed after treatment with both docetaxel and abiraterone [170,171]. Antonarakis et al. also recently reported that a splice variant of the androgen receptor (AR-V7) could be detected in CTCs from CRPC patients [172]. AR-V7-positive patients had lower PSA response rates to abiraterone and enzalutamide than AR-V7-negative patients ( 0 vs $68 \%[\mathrm{p}=0.004]$ and 0 vs $53 \%[p=0.004]$, respectively). They also had a shorter PSA PFS (median $=1.3$ months vs not reached 
[p $<0.001]$ and 1.4 vs 6.0 months [p $<0.001]$, respectively), shorter clinical or radiographic PFS (median $=2.3$ months vs not reached $[\mathrm{p}<0.001]$ and $2.1 \mathrm{vs}$ 6.1 months $[\mathrm{p}<0.001]$, respectively) and shorter OS (median $=10.6$ months vs not reached $[\mathrm{p}=0.006]$ and 5.5 months vs not reached $[\mathrm{p}=0.004]$, respectively). One limitation of this study, however, is the fact that AR-V7-positive patients had a greater overall disease burden than AR-V7-negative patients, so it is unclear whether AR-V7 represents a predictive factor of response to abiraterone and enzalutamide in CRPC or simply a marker of more advanced disease.

\section{Conclusion}

Newer molecular biomarkers allow the clinician to better evaluate patients for the detection of clinically significant prostate cancer preventing over diagnosis and overtreatment. They are becoming a powerful tool for risk-stratification and for directing treatment.

\section{Future perspective}

A possible future algorithm in the diagnosis and prognosis of PCa is demonstrated in Figure 1. Challenges still remain, however, in the development of genetic markers in the PCa population. PCa is a heterogeneous disease both within a single tumor locus (intrafocal heterogeneity) and between different tumor deposits (interfocal heterogeneity) [173]. Ongoing abnormal mutational processes give rise to extensive branching evolution and cancer clone mixing, which can be demonstrated by the coexistence of multiple cancer lineages harboring distinct ERG fusions within a single PCa nodule [174]. There is a field effect of molecular changes as benign areas of the same prostate can show cancer-related genetic changes [175]. Discordance may also exist between metastatic versus primary lesions, so tissue sampling is of the utmost importance. The morbidity and costs associated with biopsy of metastatic or primary lesions, however, may dissuade patients from

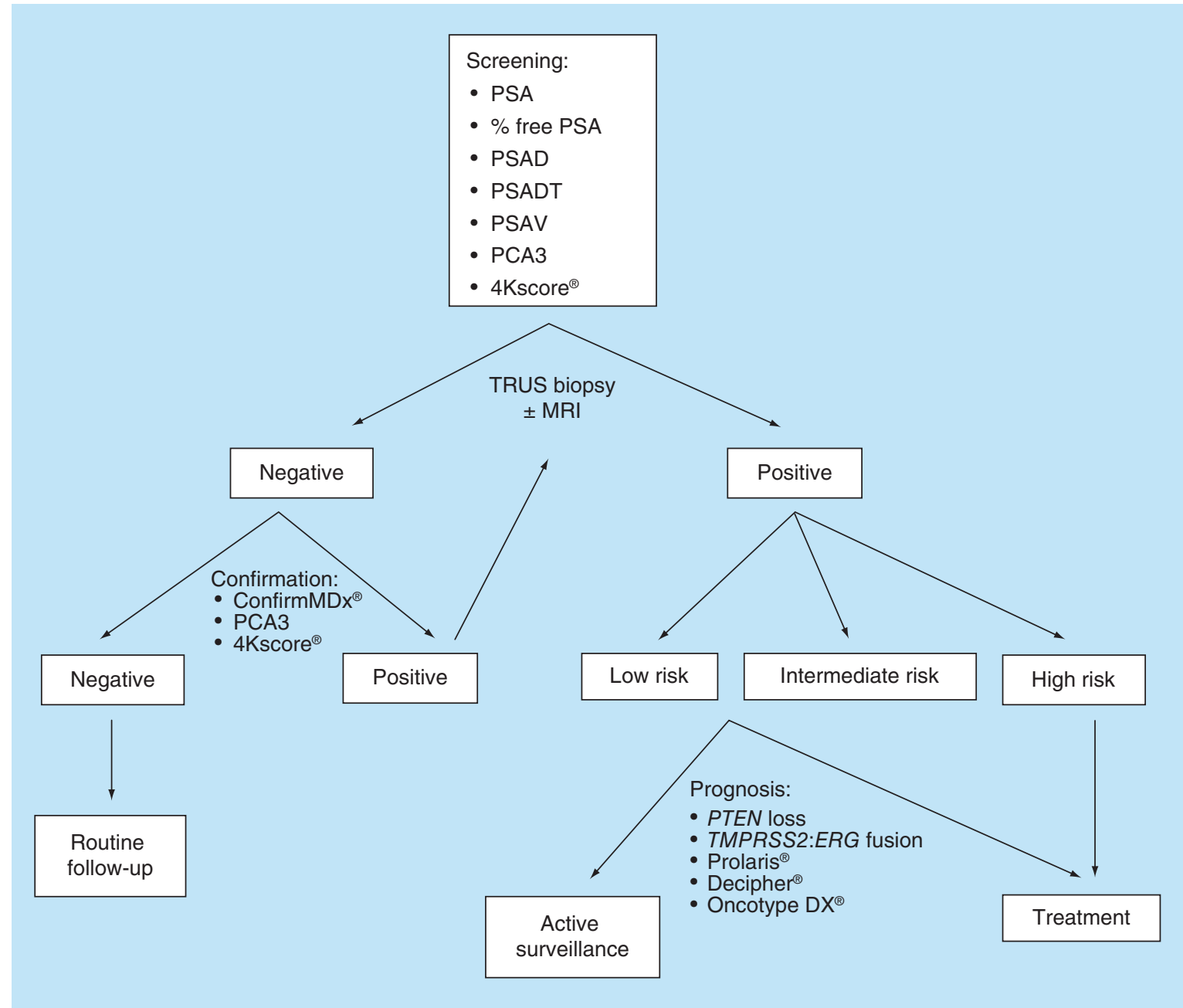

Figure 1. Proposed algorithm for prostate cancer management.

PSA: Prostate-specific antigen; PSAD: PSA density; PSADT: PSA doubling time; PSAV: PSA velocity; TRUS: Transrectal ultrasound. 
participation in clinical trials. CTCs in the peripheral blood may offer an alternative option for disease monitoring since genetic and molecular changes in prostate CTCs have shown to predict response to therapy in metastatic lesions.

Second, although combinations of multiple markers (gene-expression profiles) have been tested as predictors of disease prognosis and clinical response in $\mathrm{PCa}$ with three commercially approved assays available, there seems to be no commonality in the prognostic genes identified, raising questions as to the randomness of these identified biomarkers and whether they just represent downstream pathways in carcinogenesis rather than inciting genetic mutations. These genetic panels also have to be validated in future prospective studies to truly gain credibility, and testing them head-to-head with known clinicopathological risk factors will ultimately determine their added prognostic value. Inflammatory biomarker panels may provide an alternative option in the near future as emerging data suggest that an improved understanding of the tumor-host microenvironment within the prostate will lead to new immunobiomarkers that may be very informative.

Finally, although large-scale efforts have been placed into identifying genetic markers and molecular indica- tors in the diagnosis and prognosis of $\mathrm{PCa}$, investigation into PCa prevention is still lacking. Despite knowledge of inherited alleles that contribute to PCa development, genetic manipulation of these susceptibility loci has still not been possible to reduce the incidence of disease and the burden of treatment in a high-risk population. Additionally, whether genetic or biochemical engineering can be used to change the natural history and the overall aggressiveness of $\mathrm{PCa}$ is still not known and may be the subject of future investigation.

\section{Financial \& competing interests disclosure}

The authors have no relevant affiliations or financial involvement with any organization or entity with a financial interest in or financial conflict with the subject matter or materials discussed in the manuscript. This includes employment, consultancies, honoraria, stock ownership or options, expert testimony, grants or patents received or pending, or royalties.

No writing assistance was utilized in the production of this manuscript.

\section{Open access}

This work is licensed under the Creative Commons Attribution 4.0 License. To view a copy of this license, visit http://creativecommons.org/licenses/by/4.0/

\section{Executive summary}

- Advances in the genotyping and understanding of biochemical pathways involved in prostate cancer (PCa) development and carcinogenesis have led to the possibility of personalized genetic profiling of primary and metastatic tumor cells.

- These biomolecular signatures may become readily available for routine clinical decision-making in PCa patients ranging from the need for repeat biopsy, initial treatment selection, decisions about adjuvant therapy or selection of treatments for advanced disease.

- Large clinical trials involving multi-institutional collaborations will be necessary to prospectively validate the utility of these genetic biomarkers in the diagnosis and treatment of PCa.

- Future research should also focus on biogenetic engineering in PCa prevention as well as targeted agents to minimize disease aggressiveness in order to reduce the incidence and burden of this malignancy.

\section{References}

Papers of special note have been highlighted as:

- of interest; $\bullet \bullet$ of considerable interest

1 Siegel R, Ma J, Zou Z, Jemal A. Cancer statistics, 2014. CA Cancer J. Clin. 64(1), 9-29 (2014).

2 Klotz L, Vesprini D, Sethukavalan P et al. Long-term follow-up of a large active surveillance cohort of patients with prostate cancer. J. Clin. Oncol. 33(3), 272-277 (2015).

3 Hugosson J, Carlsson S. Overdetection in screening for prostate cancer. Curr. Opin. Urol. 24(3), 256-263 (2014).

4 Sanda MG, Dunn RL, Michalski J et al. Quality of life and satisfaction with outcome among prostate-cancer survivors. N. Engl. J. Med. 358(12), 1250-1261 (2008).

5 Klotz L. Prostate cancer overdiagnosis and overtreatment. Curr. Opin. Endocrinol. Diabetes Obes. 20(3), 204-209 (2013).
6 Barbieri CE, Bangma CH, Bjartell A et al. The mutational landscape of prostate cancer. Eur. Urol. 64(4), 567-576 (2013).

7 Jeronimo C, Bastian PJ, Bjartell A et al. Epigenetics in prostate cancer: biologic and clinical relevance. Eur. Urol. 60(4), 753-766 (2011).

8 Giskeodegard GF, Bertilsson H, Selnaes KM et al. Spermine and citrate as metabolic biomarkers for assessing prostate cancer aggressiveness. PLoS ONE 8(4), e62375 (2013).

9 Zhang VY, Westphalen A, Delos Santos L et al. The role of metabolic imaging in radiation therapy of prostate cancer. NMR Biomed. 27(1), 100-111 (2014).

10 Huang G, Liu X, Jiao L et al. Metabolomic evaluation of the response to endocrine therapy in patients with prostate cancer. Eur. J. Pharmacol. 729 132-137 (2014). 
11 Kumar V, Dwivedi DK, Jagannathan NR. High-resolution NMR spectroscopy of human body fluids and tissues in relation to prostate cancer. NMR Biomed. 27(1), 80-89 (2014).

12 Lucarelli G, Rutigliano M, Galleggiante V et al. Metabolomic profiling for the identification of novel diagnostic markers in prostate cancer. Expert Rev. Mol. Diagn. doi:10.1586/14737159.2015.1069711 (2015) (Epub ahead of print)

13 Shukla-Dave A, Hricak H, Akin O et al. Preoperative nomograms incorporating magnetic resonance imaging and spectroscopy for prediction of insignificant prostate cancer. BJU Int. 109(9), 1315-1322 (2012).

14 Thapar R, Titus MA. Recent advances in metabolic profiling and imaging of prostate cancer. Curr. Metabolomics 2(1), 53-69 (2014).

15 Lichtenstein P, Holm NV, Verkasalo PK et al. Environmental and heritable factors in the causation of cancer - analyses of cohorts of twins from Sweden, Denmark, and Finland. N. Engl. J. Med. 343(2), 78-85 (2000).

16 Al Olama AA, Dadaev T, Hazelett DJ et al. Multiple novel prostate cancer susceptibility signals identified by finemapping of known risk loci among Europeans. Hum. Mol. Genet. doi:10.1093/hmg/ddv203 (2015) (Epub ahead of print).

17 Al Olama AA, Kote-Jarai Z, Berndt SI et al. A meta-analysis of 87,040 individuals identifies 23 new susceptibility loci for prostate cancer. Nat. Genet. 46(10), 1103-1109 (2014).

18 Zheng SL, Sun J, Wiklund F et al. Cumulative association of five genetic variants with prostate cancer. N. Engl. J. Med. 358(9), 910-919 (2008).

-. Discovery of genetic susceptibility loci associated with prostate cancer diagnosis and prognosis.

19 Saunders EJ, Dadaev T, Leongamornlert DA et al. Finemapping the HOXB region detects common variants tagging a rare coding allele: evidence for synthetic association in prostate cancer. PLoS Genet. 10(2), e1004129 (2014).

20 Ewing CM, Ray AM, Lange EM et al. Germline mutations in HOXB13 and prostate-cancer risk. N. Engl. J. Med. 366(2), 141-149 (2012).

21 Byrski T, Gronwald J, Huzarski T et al. Pathologic complete response rates in young women with $B R C A 1$-positive breast cancers after neoadjuvant chemotherapy. J. Clin. Oncol. 28(3), 375-379 (2010).

22 Yang D, Khan S, Sun Y et al. Association of BRCA1 and $B R C A 2$ mutations with survival, chemotherapy sensitivity, and gene mutator phenotype in patients with ovarian cancer. JAMA 306(14), 1557-1565 (2011).

23 Kote-Jarai Z, Leongamornlert D, Saunders E et al. BRCA2 is a moderate penetrance gene contributing to young-onset prostate cancer: implications for genetic testing in prostate cancer patients. Br. J. Cancer 105(8), 1230-1234 (2011).

24 Castro E, Goh C, Olmos D et al. Germline BRCA mutations are associated with higher risk of nodal involvement, distant metastasis, and poor survival outcomes in prostate cancer. $J$. Clin. Oncol. 31(14), 1748-1757 (2013).
25 Castro E, Goh C, Leongamornlert D et al. Effect of BRCA mutations on metastatic relapse and cause-specific survival after radical treatment for localised prostate cancer. Eur. Urol. 68(2), 186-193 (2014).

26 Risbridger GP, Taylor RA, Clouston D et al. Patient-derived xenografts reveal that intraductal carcinoma of the prostate is a prominent pathology in BRCA2 mutation carriers with prostate cancer and correlates with poor prognosis. Eur. Urol. 67(3), 496-503 (2015).

27 Macinnis RJ, Antoniou AC, Eeles RA et al. A risk prediction algorithm based on family history and common genetic variants: application to prostate cancer with potential clinical impact. Genet. Epidemiol. 35(6), 549-556 (2011).

28 Ross AE, Loeb S, Landis P et al. Prostate-specific antigen kinetics during follow-up are an unreliable trigger for intervention in a prostate cancer surveillance program. J. Clin. Oncol. 28(17), 2810-2816 (2010).

29 Labrie F, Dupont A, Suburu R et al. Serum prostate specific antigen as pre-screening test for prostate cancer. J. Urol. 147(3 Pt 2), 846-851; discussion 851-842 (1992).

30 Morgan TO, Jacobsen SJ, Mccarthy WF, Jacobson DJ, Mcleod DG, Moul JW. Age-specific reference ranges for prostate-specific antigen in black men. $N$. Engl. J. Med. 335(5), 304-310 (1996).

31 Oesterling JE. Age-specific reference ranges for serum PSA. N. Engl. J. Med. 335(5), 345-346 (1996).

32 Jansen FH, Roobol M, Jenster G, Schroder FH, Bangma $\mathrm{CH}$. Screening for prostate cancer in 2008 II: the importance of molecular subforms of prostate-specific antigen and tissue kallikreins. Eur. Urol. 55(3), 563-574 (2009).

33 Gudmundsson J, Besenbacher S, Sulem P et al. Genetic correction of PSA values using sequence variants associated with PSA levels. Sci. Transl. Med. 2(62), 62ra92 (2010).

34 Wallner LP, Frencher SK, Hsu JW et al. Changes in serum prostate-specific antigen levels and the identification of prostate cancer in a large managed care population. BJU Int. 111(8), 1245-1252 (2013).

35 Van Gils MP, Hessels D, Van Hooij O et al. The timeresolved fluorescence-based PCA3 test on urinary sediments after digital rectal examination; a Dutch multicenter validation of the diagnostic performance. Clin. Cancer Res. 13(3), 939-943 (2007).

36 Khan MA, Partin AW, Rittenhouse HG et al. Evaluation of proprostate specific antigen for early detection of prostate cancer in men with a total prostate specific antigen range of 4.0 to $10.0 \mathrm{ng} / \mathrm{ml}$. J. Urol. 170(3), 723-726 (2003).

- Discovery of a kallikrein panel to predict prostate cancer detection in a randomized, screening population of European men.

37 Van Neste L, Herman JG, Otto G, Bigley JW, Epstein JI, Van Criekinge W. The epigenetic promise for prostate cancer diagnosis. Prostate 72(11), 1248-1261 (2012).

- Discovery of an epigenetic assay to detect occult prostate cancer in histopathologically negative biopsies, demonstrating a field effect to the disease.

38 Eggener SE, Roehl KA, Catalona WJ. Predictors of subsequent prostate cancer in men with a prostate specific 
antigen of 2.6 to $4.0 \mathrm{ng} / \mathrm{ml}$ and an initially negative biopsy. J. Urol. 174(2), 500-504 (2005).

39 Mohler J, Bahnson RR, Boston B et al. NCCN clinical practice guidelines in oncology: prostate cancer. J. Natl Compr. Canc. Netw. 8(2), 162-200 (2010).

40 Vickers AJ, Brewster SF. PSA velocity and doubling time in diagnosis and prognosis of prostate cancer. Br. J. Med. Surg. Urol. 5(4), 162-168 (2012).

41 Ulmert D, Serio AM, O'Brien MF et al. Long-term prediction of prostate cancer: prostate-specific antigen (PSA) velocity is predictive but does not improve the predictive accuracy of a single PSA measurement 15 years or more before cancer diagnosis in a large, representative, unscreened population. J. Clin. Oncol. 26(6), 835-841 (2008).

42 Vickers AJ, Savage C, O’Brien MF, Lilja H. Systematic review of pretreatment prostate-specific antigen velocity and doubling time as predictors for prostate cancer. J. Clin. Oncol. 27(3), 398-403 (2009).

43 Vickers AJ, Wolters T, Savage CJ et al. Prostate-specific antigen velocity for early detection of prostate cancer: result from a large, representative, population-based cohort. Eur. Urol. 56(5), 753-760 (2009).

44 Wolters T, Roobol MJ, Bangma CH, Schroder FH. Is prostate-specific antigen velocity selective for clinically significant prostate cancer in screening? European Randomized Study of Screening for Prostate Cancer (Rotterdam). Eur. Urol. 55(2), 385-392 (2009).

45 Vickers AJ, Wolters T, Savage CJ et al. Prostate specific antigen velocity does not aid prostate cancer detection in men with prior negative biopsy. J. Urol. 184(3), 907-912 (2010).

46 Andriole GL, Bostwick D, Brawley OW et al. The effect of dutasteride on the usefulness of prostate specific antigen for the diagnosis of high grade and clinically relevant prostate cancer in men with a previous negative biopsy: results from the REDUCE study. J. Urol. 185(1), 126-131 (2011).

47 Thompson IM, Pauler Ankerst D, Chi C et al. Prediction of prostate cancer for patients receiving finasteride: results from the Prostate Cancer Prevention Trial. J. Clin. Oncol. 25(21), 3076-3081 (2007).

48 Orsted DD, Bojesen SE, Kamstrup PR, Nordestgaard BG. Long-term prostate-specific antigen velocity in improved classification of prostate cancer risk and mortality. Eur. Urol. 64(3), 384-393 (2013).

- Landmark study demonstrating the ability of urinary PCA3 to predict the probability of a positive repeat prostate biopsy in men with one or two prior negative biopsies.

49 Vickers AJ, Thompson IM, Klein E, Carroll PR, Scardino PT. A commentary on PSA velocity and doubling time for clinical decisions in prostate cancer. Urology 83(3), 592-596 (2014).

50 Salagierski M, Schalken JA. Molecular diagnosis of prostate cancer: PCA3 and TMPRSS2:ERG gene fusion. J. Urol. 187(3), 795-801 (2012).

51 Schroder FH, Venderbos LD, Van Den Bergh RC et al. Prostate cancer antigen 3: diagnostic outcomes in men presenting with urinary prostate cancer antigen 3 scores $\geq 100$. Urology 83(3), 613-616 (2014).

52 Haese A, De La Taille A, Van Poppel H et al. Clinical utility of the PCA3 urine assay in European men scheduled for repeat biopsy. Eur. Urol. 54(5), 1081-1088 (2008).

53 Jansen FH, Van Schaik RH, Kurstjens J et al. Prostatespecific antigen (PSA) isoform p2PSA in combination with total PSA and free PSA improves diagnostic accuracy in prostate cancer detection. Eur. Urol. 57(6), 921-927 (2010).

54 Lazzeri M, Haese A, De La Taille A et al. Serum isoform [-2] proPSA derivatives significantly improve prediction of prostate cancer at initial biopsy in a total PSA range of 2-10 ng/ml: a multicentric European study. Eur. Urol. 63(6), 986-994 (2013).

55 Catalona WJ, Partin AW, Sanda MG et al. A multicenter study of [-2] pro-prostate specific antigen combined with prostate specific antigen and free prostate specific antigen for prostate cancer detection in the 2.0 to $10.0 \mathrm{ng} / \mathrm{ml}$ prostate specific antigen range. J. Urol. 185(5), 1650-1655 (2011).

56 Loeb S, Sanda MG, Broyles DL et al. The prostate health index selectively identifies clinically significant prostate cancer. J. Urol. 193(4), 1163-1169 (2015).

57 Vickers AJ, Cronin AM, Aus G et al. A panel of kallikrein markers can reduce unnecessary biopsy for prostate cancer: data from the European Randomized Study of Prostate Cancer Screening in Goteborg, Sweden. BMC Med. 619 (2008).

58 Vickers AJ, Cronin AM, Roobol MJ et al. A four-kallikrein panel predicts prostate cancer in men with recent screening: data from the European Randomized Study of Screening for Prostate Cancer, Rotterdam. Clin. Cancer Res. 16(12), 3232-3239 (2010)

59 Benchikh A, Savage C, Cronin A et al. A panel of kallikrein markers can predict outcome of prostate biopsy following clinical work-up: an independent validation study from the European Randomized Study of Prostate Cancer screening, France. BMC Cancer 10, 635 (2010).

- Discovery of the TMPRSS2:ERG gene fusion and its association with prostate cancer diagnosis and prognosis.

60 Gupta A, Roobol MJ, Savage CJ et al. A four-kallikrein panel for the prediction of repeat prostate biopsy: data from the European Randomized Study of Prostate Cancer screening in Rotterdam, Netherlands. Br. J. Cancer 103(5), 708-714 (2010).

61 Nordstrom T, Vickers A, Assel M, Lilja H, Gronberg H, Eklund M. Comparison between the four-kallikrein panel and prostate health index for predicting prostate cancer. Eur. Urol. 68(1), 139-146 (2015).

62 Stattin P, Vickers AJ, Sjoberg DD et al. Improving the specificity of screening for lethal prostate cancer using prostate-specific antigen and a panel of kallikrein markers: a nested case-control study. Eur. Urol. 68(2), 207-213 (2015).

63 Braun K, Sjoberg DD, Vickers AJ, Lilja H, Bjartell AS. A four-kallikrein panel predicts high-grade cancer on biopsy: independent validation in a community cohort. Eur. Urol. doi:10.1016/j.eururo.2015.04.028 (2015) (Epub ahead of print). 
64 Tomlins SA, Rhodes DR, Perner S et al. Recurrent fusion of TMPRSS2 and ETS transcription factor genes in prostate cancer. Science 310(5748), 644-648 (2005).

65 Hessels D, Smit FP, Verhaegh GW, Witjes JA, Cornel EB, Schalken JA. Detection of TMPRSS2-ERG fusion transcripts and prostate cancer antigen 3 in urinary sediments may improve diagnosis of prostate cancer. Clin. Cancer Res. 13(17), 5103-5108 (2007).

66 Salami SS, Schmidt F, Laxman B et al. Combining urinary detection of TMPRSS2:ERG and PCA3 with serum PSA to predict diagnosis of prostate cancer. Urol. Oncol. 31(5), 566-571 (2013).

67 Whitaker HC, Kote-Jarai Z, Ross-Adams H et al. The rs10993994 risk allele for prostate cancer results in clinically relevant changes in microseminoprotein-beta expression in tissue and urine. PLoS ONE 5(10), e13363 (2010).

68 Harden SV, Guo Z, Epstein JI, Sidransky D. Quantitative GSTP1 methylation clearly distinguishes benign prostatic tissue and limited prostate adenocarcinoma. J. Urol. 169(3), 1138-1142 (2003).

69 Jeronimo C, Henrique R, Hoque MO et al. A quantitative promoter methylation profile of prostate cancer. Clin. Cancer Res. 10(24), 8472-8478 (2004).

70 Agathanggelou A, Cooper WN, Latif F. Role of the Rasassociation domain family 1 tumor suppressor gene in human cancers. Cancer Res. 65(9), 3497-3508 (2005).

71 Nakayama M, Gonzalgo ML, Yegnasubramanian S, Lin X, De Marzo AM, Nelson WG. GSTP1 CpG island hypermethylation as a molecular biomarker for prostate cancer. J. Cell. Biochem. 91(3), 540-552 (2004).

72 Mehrotra J, Varde S, Wang H et al. Quantitative, spatial resolution of the epigenetic field effect in prostate cancer. Prostate 68(2), 152-160 (2008).

73 Nonn L, Ananthanarayanan V, Gann PH. Evidence for field cancerization of the prostate. Prostate 69(13), 1470-1479 (2009).

74 Chai H, Brown RE. Field effect in cancer-an update. Ann. Clin. Lab. Sci. 39(4), 331-337 (2009).

75 Stewart GD, Van Neste L, Delvenne P et al. Clinical utility of an epigenetic assay to detect occult prostate cancer in histopathologically negative biopsies: results of the MATLOC study. J. Urol. 189(3), 1110-1116 (2013).

76 Partin AW, Van Neste L, Klein EA et al. Clinical validation of an epigenetic assay to predict negative histopathological results in repeat prostate biopsies. J. Urol. 192(4), 1081-1087 (2014).

77 Wojno KJ, Costa FJ, Cornell RJ et al. Reduced rate of repeated prostate biopsies observed in confirmMDx clinical utility field study. Am. Health Drug Benefits 7(3), 129-134 (2014).

78 Van Den Bergh RC, Roemeling S, Roobol MJ, Wolters T, Schroder FH, Bangma CH. Prostate-specific antigen kinetics in clinical decision-making during active surveillance for early prostate cancer--a review. Eur. Urol. 54(3), 505-516 (2008).

79 Khatami A, Aus G, Damber JE, Lilja H, Lodding P, Hugosson J. PSA doubling time predicts the outcome after active surveillance in screening-detected prostate cancer: results from the European randomized study of screening for prostate cancer, Sweden section. Int. J. Cancer 120(1), 170-174 (2007).

80 Soloway MS, Soloway CT, Williams S, Ayyathurai R, Kava B, Manoharan M. Active surveillance; a reasonable management alternative for patients with prostate cancer: the Miami experience. BJU Int. 101(2), 165-169 (2008).

81 Whitson JM, Porten SP, Hilton JF et al. The relationship between prostate specific antigen change and biopsy progression in patients on active surveillance for prostate cancer. J. Urol. 185(5), 1656-1660 (2011).

82 Iremashvili V, Manoharan M, Lokeshwar SD, Rosenberg DL, Pan D, Soloway MS. Comprehensive analysis of postdiagnostic prostate-specific antigen kinetics as predictor of a prostate cancer progression in active surveillance patients. BJU Int. 111(3), 396-403 (2013).

83 San Francisco IF, Werner L, Regan MM, Garnick MB, Bubley G, Dewolf WC. Risk stratification and validation of prostate specific antigen density as independent predictor of progression in men with low risk prostate cancer during active surveillance. J. Urol. 185(2), 471-476 (2011).

84 Patel HD, Feng Z, Landis P, Trock BJ, Epstein JI, Carter HB. Prostate specific antigen velocity risk count predicts biopsy reclassification for men with very low risk prostate cancer. J. Urol. 191(3), 629-637 (2014).

85 Cary KC, Cowan JE, Sanford M et al. Predictors of pathologic progression on biopsy among men on active surveillance for localized prostate cancer: the value of the pattern of surveillance biopsies. Eur. Urol. 66(2), 337-342 (2014).

86 Barayan GA, Brimo F, Begin LR et al. Factors influencing disease progression of prostate cancer under active surveillance: a McGill University Health Center cohort. BJU Int. 114(6b), E99-E104 (2014).

87 Dall'Era MA, Konety BR, Cowan JE et al. Active surveillance for the management of prostate cancer in a contemporary cohort. Cancer 112(12), 2664-2670 (2008).

88 Venkitaraman R, Norman A, Woode-Amissah R et al. Predictors of histological disease progression in untreated, localized prostate cancer. J. Urol. 178 (3 Pt 1), 833-837 (2007).

89 Loeb S, Han M, Roehl KA, Antenor JA, Catalona WJ. Accuracy of prostate weight estimation by digital rectal examination versus transrectal ultrasonography. J. Urol. 173(1), 63-65 (2005).

90 Makarov DV, Isharwal S, Sokoll LJ et al. Pro-prostatespecific antigen measurements in serum and tissue are associated with treatment necessity among men enrolled in expectant management for prostate cancer. Clin. Cancer Res. 15(23), 7316-7321 (2009).

91 Tosoian JJ, Loeb S, Feng Z et al. Association of [-2]proPSA with biopsy reclassification during active surveillance for prostate cancer. J. Urol. 188(4), 1131-1136 (2012).

92 Hirama H, Sugimoto M, Ito K, Shiraishi T, Kakehi Y. The impact of baseline [-2] proPSA-related indices on the prediction of pathological reclassification at 1 year during active surveillance for low-risk prostate cancer: the Japanese 
multicenter study cohort. J. Cancer Res. Clin. Oncol. 140(2), 257-263 (2014).

93 Tosoian JJ, Loeb S, Kettermann A et al. Accuracy of PCA3 measurement in predicting short-term biopsy progression in an active surveillance program. J. Urol. 183(2), 534-538 (2010).

94 Merola R, Tomao L, Antenucci A et al. PCA3 in prostate cancer and tumor aggressiveness detection on 407 high-risk patients: a National Cancer Institute experience. J. Exp. Clin. Cancer Res. 34(1), 15 (2015).

95 Nam RK, Sugar L, Yang W et al. Expression of the TMPRSS2:ERG fusion gene predicts cancer recurrence after surgery for localised prostate cancer. Br. J. Cancer 97(12), 1690-1695 (2007).

96 Nam RK, Sugar L, Wang Z et al. Expression of TMPRSS2:ERG gene fusion in prostate cancer cells is an important prognostic factor for cancer progression. Cancer Biol. Ther. 6(1), 40-45 (2007).

97 Saramaki OR, Harjula AE, Martikainen PM, Vessella RL, Tammela TL, Visakorpi T. TMPRSS2:ERG fusion identifies a subgroup of prostate cancers with a favorable prognosis. Clin. Cancer Res. 14(11), 3395-3400 (2008).

98 Steurer S, Mayer PS, Adam M et al. TMPRSS2-ERG fusions are strongly linked to young patient age in low-grade prostate cancer. Eur. Urol. 66(6), 978-981 (2014).

Dal Pra A, Lalonde E, Sykes J et al. TMPRSS2-ERG status is not prognostic following prostate cancer radiotherapy: implications for fusion status and DSB repair. Clin. Cancer Res. 19(18), 5202-5209 (2013).

100 Gopalan A, Leversha MA, Satagopan JM et al. TMPRSS2$E R G$ gene fusion is not associated with outcome in patients treated by prostatectomy. Cancer Res. 69(4), 1400-1406 (2009).

101 Hoogland AM, Jenster G, Van Weerden WM et al. ERG immunohistochemistry is not predictive for PSA recurrence, local recurrence or overall survival after radical prostatectomy for prostate cancer. Mod. Pathol. 25(3), 471-479 (2012).

102 Minner S, Enodien M, Sirma H et al. ERG status is unrelated to PSA recurrence in radically operated prostate cancer in the absence of antihormonal therapy. Clin. Cancer Res. 17(18), 5878-5888 (2011).

103 Pettersson A, Graff RE, Bauer SR et al. The TMPRSS2:ERG rearrangement, $E R G$ expression, and prostate cancer outcomes: a cohort study and meta-analysis. Cancer Epidemiol. Biomarkers Prev. 21(9), 1497-1509 (2012).

104 FitzGerald LM, Agalliu I, Johnson K et al. Association of TMPRSS2-ERG gene fusion with clinical characteristics and outcomes: results from a population-based study of prostate cancer. BMC Cancer 8230 (2008).

105 Boormans JL, Porkka K, Visakorpi T, Trapman J. Confirmation of the association of TMPRSS2 (exon 0):ERG expression and a favorable prognosis of primary prostate cancer. Eur. Urol. 60(1), 183-184 (2011).

106 Berg KD, Vainer B, Thomsen FB et al. ERG protein expression in diagnostic specimens is associated with increased risk of progression during active surveillance for prostate cancer. Eur. Urol. 66(5), 851-860 (2014).
107 Lin DW, Newcomb LF, Brown EC et al. Urinary TMPRSS2:ERG and PCA3 in an active surveillance cohort: results from a baseline analysis in the Canary Prostate Active Surveillance Study. Clin. Cancer Res. 19(9), 2442-2450 (2013).

108 Attard G, Clark J, Ambroisine L et al. Duplication of the fusion of TMPRSS2 to ERG sequences identifies fatal human prostate cancer. Oncogene 27(3), 253-263 (2008).

109 Hagglof C, Hammarsten P, Stromvall K et al. TMPRSS2$E R G$ expression predicts prostate cancer survival and associates with stromal biomarkers. PLoS ONE 9(2), e86824 (2014).

110 Demichelis F, Fall K, Perner S et al. TMPRSS2:ERG gene fusion associated with lethal prostate cancer in a watchful waiting cohort. Oncogene 26(31), 4596-4599 (2007).

111 Qi M, Yang X, Zhang F et al. ERG rearrangement is associated with prostate cancer-related death in Chinese prostate cancer patients. PLoS ONE 9(2), e84959 (2014).

112 Boormans JL, Hermans KG, Made AC et al. Expression of the androgen-regulated fusion gene TMPRSS2-ERG does not predict response to endocrine treatment in hormonenaive, node-positive prostate cancer. Eur. Urol. 57(5), 830-835 (2010).

113 Leinonen KA, Tolonen TT, Bracken $\mathrm{H}$ et al. Association of SPINK1 expression and TMPRSS2:ERG fusion with prognosis in endocrine-treated prostate cancer. Clin. Cancer Res. 16(10), 2845-2851 (2010).

114 Cheville JC, Karnes RJ, Therneau TM et al. Gene panel model predictive of outcome in men at high-risk of systemic progression and death from prostate cancer after radical retropubic prostatectomy. J. Clin. Oncol. 26(24), 3930-3936 (2008).

115 Gasi Tandefelt D, Boormans JL, Van Der Korput HA, Jenster GW, Trapman J. A 36-gene signature predicts clinical progression in a subgroup of ERG-positive prostate cancers. Eur. Urol. 64(6), 941-950 (2013).

116 Karnes RJ, Cheville JC, Ida CM et al. The ability of biomarkers to predict systemic progression in men with highrisk prostate cancer treated surgically is dependent on ERG status. Cancer Res. 70 (22), 8994-9002 (2010).

117 Taylor BS, Schultz N, Hieronymus $\mathrm{H}$ et al. Integrative genomic profiling of human prostate cancer. Cancer Cell 18(1), 11-22 (2010).

118 Tsuchiya N, Slezak JM, Lieber MM, Bergstralh EJ, Jenkins $\mathrm{RB}$. Clinical significance of alterations of chromosome 8 detected by fluorescence in situ hybridization analysis in pathologic organ-confined prostate cancer. Genes Chromosomes Cancer 34(4), 363-371 (2002).

119 Locke JA, Zafarana G, Ishkanian AS et al. NKX3.1 haploinsufficiency is prognostic for prostate cancer relapse following surgery or image-guided radiotherapy. Clin. Cancer Res. 18(1), 308-316 (2012).

120 Liu W, Xie CC, Thomas CY et al. Genetic markers associated with early cancer-specific mortality following prostatectomy. Cancer 119(13), 2405-2412 (2013).

121 Zafarana G, Ishkanian AS, Malloff CA et al. Copy number alterations of c-MYC and PTEN are prognostic factors for 
relapse after prostate cancer radiotherapy. Cancer 118(16), 4053-4062 (2012).

122 Paris PL, Andaya A, Fridlyand J et al. Whole genome scanning identifies genotypes associated with recurrence and metastasis in prostate tumors. Hum. Mol. Genet. 13(13), 1303-1313 (2004).

123 Paris PL, Weinberg V, Albo G et al. A group of genome-based biomarkers that add to a Kattan nomogram for predicting progression in men with high-risk prostate cancer. Clin. Cancer Res. 16(1), 195-202 (2010).

124 Cairns P, Okami K, Halachmi S et al. Frequent inactivation of PTEN/MMAC1 in primary prostate cancer. Cancer Res. 57(22), 4997-5000 (1997).

125 Saal LH, Johansson P, Holm K et al. Poor prognosis in carcinoma is associated with a gene expression signature of aberrant PTEN tumor suppressor pathway activity. Proc. Natl Acad. Sci. USA 104(18), 7564-7569 (2007).

126 Leinonen KA, Saramaki OR, Furusato B et al. Loss of PTEN is associated with aggressive behavior in ERG-positive prostate cancer. Cancer Epidemiol. Biomarkers Prev. 22(12), 2333-2344 (2013).

127 Yoshimoto M, Joshua AM, Cunha IW et al. Absence of TMPRSS2:ERG fusions and PTEN losses in prostate cancer is associated with a favorable outcome. Mod. Pathol. 21(12), 1451-1460 (2008).

128 Yoshimoto M, Cunha IW, Coudry RA et al. FISH analysis of 107 prostate cancers shows that PTEN genomic deletion is associated with poor clinical outcome. Br. J. Cancer 97(5), 678-685 (2007).

129 Krohn A, Diedler T, Burkhardt L et al. Genomic deletion of PTEN is associated with tumor progression and early PSA recurrence in $E R G$ fusion-positive and fusion-negative prostate cancer. Am. J. Pathol. 181(2), 401-412 (2012).

130 Reid AH, Attard G, Ambroisine L et al. Molecular characterisation of $E R G, E T V 1$ and PTEN gene loci identifies patients at low and high risk of death from prostate cancer. Br. J. Cancer 102(4), 678-684 (2010).

131 McCall P, Witton CJ, Grimsley S, Nielsen KV, Edwards J. Is PTEN loss associated with clinical outcome measures in human prostate cancer? Br. J. Cancer 99(8), 1296-1301 (2008).

132 Ferraldeschi R, Nava Rodrigues D, Riisnaes R et al. PTEN protein loss and clinical outcome from castration-resistant prostate cancer treated with abiraterone acetate. Eur. Urol. 67(4), 795-802 (2015).

133 Halvorsen OJ, Haukaas SA, Akslen LA. Combined loss of PTEN and p27 expression is associated with tumor cell proliferation by Ki- 67 and increased risk of recurrent disease in localized prostate cancer. Clin. Cancer Res. 9(4), 1474-1479 (2003).

134 Li Y, Su J, Dingzhang X et al. PTEN deletion and heme oxygenase-1 overexpression cooperate in prostate cancer progression and are associated with adverse clinical outcome. J. Pathol. 224(1), 90-100 (2011).

135 Ahmad I, Patel R, Singh LB et al. HER2 overcomes PTEN (loss)-induced senescence to cause aggressive prostate cancer. Proc. Natl Acad. Sci. USA 108(39), 16392-16397 (2011).
136 Troyer DA, Jamaspishvili T, Wei W et al. A multicenter study shows PTEN deletion is strongly associated with seminal vesicle involvement and extracapsular extension in localized prostate cancer. Prostate 75(11), 1206-1215 (2015).

137 Lotan TL, Carvalho FL, Peskoe SB et al. PTEN loss is associated with upgrading of prostate cancer from biopsy to radical prostatectomy. Mod. Pathol. 28(1), 128-137 (2015).

138 Bastian PJ, Palapattu GS, Yegnasubramanian S et al. Prognostic value of preoperative serum cell-free circulating DNA in men with prostate cancer undergoing radical prostatectomy. Clin. Cancer Res. 13 (18 Pt 1), 5361-5367 (2007).

139 Ross RW, Galsky MD, Scher HI et al. A whole-blood RNA transcript-based prognostic model in men with castrationresistant prostate cancer: a prospective study. Lancet Oncol. 13(11), 1105-1113 (2012).

140 Olmos D, Brewer D, Clark J et al. Prognostic value of blood mRNA expression signatures in castration-resistant prostate cancer: a prospective, two-stage study. Lancet Oncol. 13(11), 1114-1124 (2012).

- Discovery study of an RNA-based cell cycle proliferation gene panel as a prognostic marker in prostate cancer.

141 Brase JC, Johannes M, Schlomm T et al. Circulating miRNAs are correlated with tumor progression in prostate cancer. Int. J. Cancer 128(3), 608-616 (2011).

142 Danila DC, Anand A, Schultz N et al. Analytic and clinical validation of a prostate cancer-enhanced messenger RNA detection assay in whole blood as a prognostic biomarker for survival. Eur. Urol. 65(6), 1191-1197 (2014).

143 Dijkstra S, Leyten GH, Jannink SA et al. KLK3, PCA3, and TMPRSS2-ERG expression in the peripheral blood mononuclear cell fraction from castration-resistant prostate cancer patients and response to docetaxel treatment. Prostate 74(12), 1222-1230 (2014).

144 Scher HI, Heller G, Molina A et al. Circulating tumor cell biomarker panel as an individual-level surrogate for survival in metastatic castration-resistant prostate cancer. J. Clin. Oncol. 33(12), 1348-1355 (2015).

145 Cuzick J, Swanson GP, Fisher G et al. Prognostic value of an RNA expression signature derived from cell cycle proliferation genes in patients with prostate cancer: a retrospective study. Lancet Oncol. 12(3), 245-255 (2011).

146 Pepe MS, Feng Z, Janes H, Bossuyt PM, Potter JD. Pivotal evaluation of the accuracy of a biomarker used for classification or prediction: standards for study design. J. Natl Cancer Inst. 100 (20), 1432-1438 (2008).

147 Mcshane LM, Hayes DF. Publication of tumor marker research results: the necessity for complete and transparent reporting. J. Clin. Oncol. 30(34), 4223-4232 (2012).

148 Cooperberg MR, Simko JP, Cowan JE et al. Validation of a cell-cycle progression gene panel to improve risk stratification in a contemporary prostatectomy cohort. $J$. Clin. Oncol. 31(11), 1428-1434 (2013).

149 Punnen S, Freedland SJ, Presti JC, Jr. et al. Multiinstitutional validation of the CAPRA-S score to predict disease recurrence and mortality after radical prostatectomy. Eur. Urol. 65(6), 1171-1177 (2014). 
- Discovery study of an RNA-based gene panel as a prognostic marker in prostate cancer for early clinical metastasis and cancer-specific death after radical prostatectomy. E, Ishkanian AS, Sykes jet al. Tumour genomic and microenvironmental heterogeneity for integrated prediction of 5-year biochemical recurrence of prostate cancer: a retrospective cohort study. Lancet Oncol. 15(13), 1521-1532 (2014).

151 Cuzick J, Berney DM, Fisher G et al. Prognostic value of a cell cycle progression signature for prostate cancer death in a conservatively managed needle biopsy cohort. Br. J. Cancer 106(6), 1095-1099 (2012).

152 Cooperberg MR, Freedland SJ, Pasta DJ et al. Multiinstitutional validation of the UCSF cancer of the prostate risk assessment for prediction of recurrence after radical prostatectomy. Cancer 107(10), 2384-2391 (2006).

153 Bishoff JT, Freedland SJ, Gerber L et al. Prognostic utility of the cell cycle progression score generated from biopsy in men treated with prostatectomy. J. Urol. 192(2), 409-414 (2014).

154 Crawford ED, Scholz MC, Kar AJ et al. Cell cycle progression score and treatment decisions in prostate cancer: results from an ongoing registry. Curr. Med. Res. Opin. 30(6), 1025-1031 (2014).

155 Klein EA, Cooperberg MR, Magi-Galluzzi C et al. A 17-gene assay to predict prostate cancer aggressiveness in the context of Gleason grade heterogeneity, tumor multifocality, and biopsy undersampling. Eur. Urol. 66(3), 550-560 (2014)

156 Cullen J, Rosner IL, Brand TC et al. A biopsy-based 17-gene genomic prostate score predicts recurrence after radical prostatectomy and adverse surgical pathology in a racially diverse population of men with clinically low- and intermediate-risk prostate cancer. Eur. Urol. 68(1), 123-131 (2014).

157 Erho N, Crisan A, Vergara IA et al. Discovery and validation of a prostate cancer genomic classifier that predicts early metastasis following radical prostatectomy. PLoS ONE 8(6), e66855 (2013).

158 Cooperberg MR, Davicioni E, Crisan A, Jenkins RB, Ghadessi M, Karnes RJ. Combined value of validated clinical and genomic risk stratification tools for predicting prostate cancer mortality in a high-risk prostatectomy cohort. Eur. Urol. 67(2), 326-333 (2015).

159 Karnes RJ, Bergstralh EJ, Davicioni E et al. Validation of a genomic classifier that predicts metastasis following radical prostatectomy in an at risk patient population. J. Urol. 190(6), 2047-2053 (2013).

160 Ross AE, Feng FY, Ghadessi M et al. A genomic classifier predicting metastatic disease progression in men with biochemical recurrence after prostatectomy. Prostate Cancer Prostatic Dis. 17(1), 64-69 (2014).

161 Den RB, Yousefi K, Trabulsi EJ et al. Genomic classifier identifies men with adverse pathology after radical prostatectomy who benefit from adjuvant radiation therapy. J. Clin. Oncol. 33(8), 944-951 (2015).

162 Den RB, Feng FY, Showalter TN et al. Genomic prostate cancer classifier predicts biochemical failure and metastases in patients after postoperative radiation therapy. Int J. Radiat. Oncol. Biol. Phys. 89(5), 1038-1046 (2014).

163 Ross RW, Oh WK, Xie W et al. Inherited variation in the androgen pathway is associated with the efficacy of androgendeprivation therapy in men with prostate cancer. J. Clin. Oncol. 26(6), 842-847 (2008).

164 Sharifi N, Hamada A, Sissung T et al. A polymorphism in a transporter of testosterone is a determinant of androgen independence in prostate cancer. BJU Int. 102(5), 617-621 (2008).

165 Yang M, Xie W, Mostaghel E et al. SLCO2B1 and SLCO1B3 may determine time to progression for patients receiving androgen deprivation therapy for prostate cancer. J. Clin. Oncol. 29(18), 2565-2573 (2011).

166 Andersen RJ, Mawji NR, Wang J et al. Regression of castraterecurrent prostate cancer by a small-molecule inhibitor of the amino-terminus domain of the androgen receptor. Cancer Cell 17(6), 535-546 (2010).

167 Ploussard G, Terry S, Maille P et al. Class III beta-tubulin expression predicts prostate tumor aggressiveness and patient response to docetaxel-based chemotherapy. Cancer Res. 70(22), 9253-9264 (2010).

- Landmark study demonstrating how detection of an androgen receptor splice variant in peripheral circulating tumor cells can predict response to therapy.

168 Terry S, Ploussard G, Allory Y et al. Increased expression of class III beta-tubulin in castration-resistant human prostate cancer. Br. J. Cancer 101(6), 951-956 (2009).

169 Danila DC, Fleisher M, Scher HI. Circulating tumor cells as biomarkers in prostate cancer. Clin. Cancer Res. 17(12), 3903-3912 (2011).

170 Danila DC, Anand A, Sung CC et al. TMPRSS2-ERG status in circulating tumor cells as a predictive biomarker of sensitivity in castration-resistant prostate cancer patients treated with abiraterone acetate. Eur. Urol. 60(5), 897-904 (2011).

171 Okegawa T, Itaya N, Hara H, Tambo M, Nutahara K. Circulating tumor cells as a biomarker predictive of sensitivity to docetaxel chemotherapy in patients with castration-resistant prostate cancer. Anticancer Res. 34(11), 6705-6710 (2014).

172 Antonarakis ES, Lu C, Wang $\mathrm{H}$ et al. AR-V7 and resistance to enzalutamide and abiraterone in prostate cancer. N. Engl. J. Med. 371(11), 1028-1038 (2014).

173 Boutros PC, Fraser M, Harding NJ et al. Spatial genomic heterogeneity within localized, multifocal prostate cancer. Nat. Genet. 47(7), 736-745 (2015).

174 Cooper CS, Eeles R, Wedge DC et al. Analysis of the genetic phylogeny of multifocal prostate cancer identifies multiple independent clonal expansions in neoplastic and morphologically normal prostate tissue. Nat. Genet. 47(4), 367-372 (2015).

175 Vaananen RM, Lilja H, Kauko L et al. Cancer-associated changes in the expression of TMPRSS2-ERG, PCA3, and SPINK1 in histologically benign tissue from cancerous vs noncancerous prostatectomy specimens. Urology 83(2), 511. e1-7 (2014) 